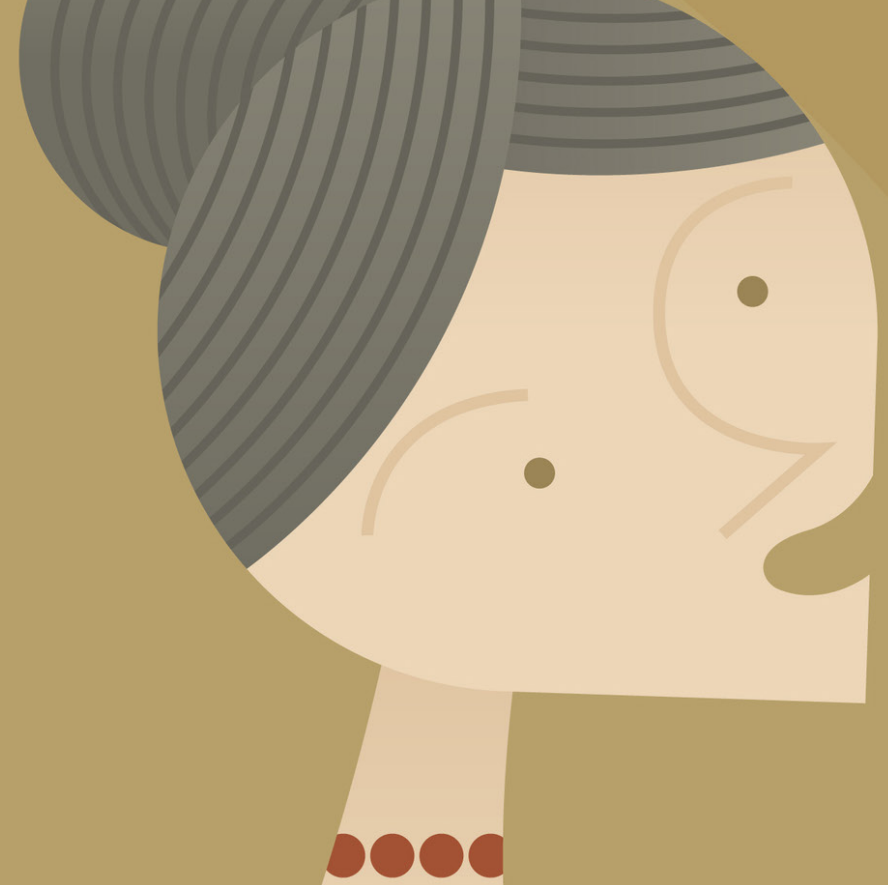


*Doutora em Educação pela Universidade do Vale do Itajaí. Professora do Serviço Nacional de Aprendizagem Industrial (Senai). Jaraguá do Sul, Santa Catarina, Brasil. E-mail: murarapatricia@gmail.com

**Doutora em Educação - Currículo e Ensino, pela Florida International University (FIU) - USA. Mestre em Educação (Currículo) pela Pontifícia Universidade Católica de São Paulo (PUC - SP). Líder do Grupo de Pesquisa de Políticas e Práticas de Currículo cadastrado no CNPQ. Professora e pesquisadora da Universidade do Vale do Itajaí no Programa de Pós-Graduação stricto sensu em Educação (Mestrado e Doutorado). Balneário Camboriú, Santa Catarina, Brasil.

E-mail: gesserv@univali.br

Recebido para publicação em: 1.9.2017

Aprovado em: 13.6.2017

\section{FORMAÇÃO DE PROFESSORES DA EDUCAÇÃO PROFISSIONAL E TECNOLÓGICA: CARACTERIZAÇÃO E DILEMAS}

\section{TRAINING FOR TEACHERS IN VOCATIONAL AND TECHNOLOGICAL EDUCATION: CHARACTERIZATION AND DILEMMAS}

\section{FORMACIÓN DE PROFESORES DE LA EDUCACIÓN PROFESIONAL Y TECNOLOGICA: CARACTERIZACION Y DILEMAS}

\section{Patricia Murara Stryhalski* Verônica Gesser**}

\section{Resumo}

No Brasil, faltam cursos de nível superior específicos para formar professores da educação profissional, particularmente pela natureza da área. Nesse caso, os professores, geralmente, são contratados como instrutores, o que pode levar a refletir criticamente sobre o assunto. Nesse sentido, este artigo tem a pretensão de discutir, teoricamente: quem pode ser professor na educação profissional; quais as competências na educação profissional e, por fim, o questionamento sobre a classificação de professor ou de instrutor da educação profissional.

Palavras-chave: Educação profissional. Formação. Professores.

\section{Abstract}

Brazil lacks specific higher education courses designed to provide training to vocational education teachers, due particularly to the nature of the area. In this case, teachers are usually hired as trainers, which calls for a critical consideration of the topic. In this regard, this paper aims to theoretically discuss: who can be a teacher and which competencies vocational training requires; and, finally, the questioning about the classification of teacher or trainer in vocational education.

Keywords: Vocational training. Education. Teachers. 


\section{Resumen}

En Brasil, faltan cursos de nivel superior específicos para formar profesores de la Educación Profesional, particularmente por la naturaleza del área. En este caso, los profesores, por lo general, son contratados como instructores, lo que puede llevarse a reflexionar críticamente sobre el tema. En este sentido, este artículo tiene la pretensión de discutir, teóricamente: quién puede ser profesor en la educación profesional; cuáles son las competencias en la formación profesional; y, por último, el cuestionamiento acerca de la clasificación de profesor o de instructor de la educación profesional.

Palabras clave: Educación profesional. Formación. Profesores.

\section{Introdução}

A Lei de Diretrizes e Bases da Educação Nacional (LDB), Lei n. 9.394/1996, não determina especificamente quem pode ser professor na educação profissional, nem para o ensino técnico nem para os cursos tecnológicos do ensino superior. Na questão da formação, a LDB menciona que pelo menos um terço dos professores do ensino superior devem ter mestrado ou doutorado. Em termos de legislação, o que se encontra em tramitação é o Parecer n. 5/2006 (CONSELHO NACIONAL DE EDUCAÇÃO, 2006), que aprecia Indicação CNE/CP n. 2/2002 sobre Diretrizes Curriculares Nacionais para Cursos de Formação de Professores para a Educação Básica, e a Resolução n. 02/97, que dispõe sobre os programas especiais de formação pedagógica de docentes para as disciplinas do currículo do ensino fundamental, do ensino médio e da educação profissional em nível médio.

Embora sejam chamados professores, a maioria dos profissionais que leciona na educação profissional não fez cursos de licenciatura, ou seja, falta na formação a parte pedagógica e didática. Assim, geralmente, são contratados como instrutores, mas cabe ressaltar que na Rede Federal, embora grande parte dos professores não seja formada em cursos de licenciatura, são contratados como professores.

Devido à preocupação que permeia a formação de professores para a educação profissional e tecnológica e à falta de formação específica para esses professores, em 2006, realizou-se o VIII Simpósio da série Educação Superior em Debate, com o tema Formação de Professores para a Educação Profissional e Tecnológica, do qual resultou a publicação de um livro intitulado Formação de Professores para Educação Profissional e Tecnológica, publicado em 2008. 
Com o crescimento da Educação Profissional e Tecnológica, como estão as políticas de formação de professores para essa modalidade?
Poucas pesquisas são realizadas sobre a formação de professores da Educação Profissional e Técnológica. Esse artigo é um recorte da pesquisa Cursos Superiores de Tecnologia no Brasil - Tradução das Políticas Públicas do Ensino Superior nos Documentos Oficiais e Perfis Profissiográficos. Em levantamento feito sobre o perfil dos professores dessa modalidade, foi possível observar que pouco se tem insvestido na formação desses profissionais, o que gera certa preocupação. Com o crescimento da Educação Profissional e Tecnológica, como estão as políticas de formação de professores para essa modalidade? Um curso de graduação seria inviável, mas que outra alternativa de formação esses professores teriam para ter o conhecimento didático-pedagógico?

Nesse sentido, o presente artigo tem como objetivo discutir teoricamente quem pode ser professor na educação profissional. Para auxiliar essa discussão, será utilizado como embasamento teórico o livro Educação Superior em Debate: Formação de Professores para a Educação Profissional e Tecnológica, bem como legislações em torno do tema. O artigo será dividido em três tópicos: no primeiro momento, será discutido quem pode ser professor na educação profissional, em seguida, as competências na educação profissional, tema de muita discussão e polêmica e, por fim, o questionamento sobre a classificação de professor ou de instrutor da educação profissional.

\section{O professor de educação profissional no mercado de trabalho atual}

Para compreender o processo dos instrutores na educação profissional, é necessário relembrar alguns aspectos importantes na história dessa oferta educacional. Kuenzer (2008) profere que, com as mudanças no mundo do trabalho, a educação profissional ganha lugar de destaque.

Nesse sentido, com as mudanças do modelo taylorista e fordista de organização do trabalho para os modelos atuais, configura-se uma nova forma de ver a educação profissional. Consequentemente, surgem diferentes demandas para seus professores, ou instrutores. Atualmente, esses profissionais têm a incumbência de ficarem atentos ao que acontece no mercado, quais as tendências e o que há de inovação. Com as transformações que ocorrem no mundo do trabalho, surgem novos métodos, os quais fazem esses professores estarem sempre em busca de novos conhecimentos para lecionar conforme as demandas do mercado.

O modelo de acumulação flexível influenciou significativamente a educação profissional. Neste regime, houve mudanças no que diz respeito ao trabalho e à educação. "[...] a concepção de trabalho enquanto "evento" e a concep- 
ção de competência enquanto práxis" (KUENZER, 2008, p. 21). Neste caso, é indispensável entender o que é competência.

\subsection{Competências para a educação profissional}

As competências são inevitáveis de serem discutidas na educação profissional e vale considerar que existem diversas críticas a elas. Na área da educação, a noção de competências tem sido discutida por diversos autores, mais precisamente no campo do currículo. O modelo de competências começa a surgir no mundo do trabalho a partir da década de 1980, com a crise do capitalismo. Essa crise veio à tona com o esgotamento do modelo taylorista e fordista. Isso implica dizer que:

Na década de 90 [do século XX], o aprofundamento da globalização das atividades capitalistas e a crescente busca de competitividade levaram ao alinhamento definitivo das políticas de recursos humanos às estratégias empresariais, incorporando a prática organizacional o conceito de competências (DELUIZ, 2001, p. 2).

No contexto escolar, competências são um tema de vital importância para o setor empregatício, inclusive estão citadas nas referências curriculares da educação. A formação escolar deve possibilitar aos alunos condições para desenvolver competência e consciência profissional, e não se restringir ao ensino de habilidades imediatamente demandadas pelo mercado de trabaIho (BRASIL, 1997, p. 34).

Kuenzer (1999) complementa que, diante das novas formas de organização do trabalho, o individual é posto em segundo plano, abrindo as portas para o coletivo. A essa competência científico-tecnológica articula-se a demanda por competência ética, na dimensão de compromisso político com a qualidade da vida social e produtiva (KUENZER, 1999, p.1).

Nesse sentido, Rios (2003) faz uma observação na relação entre política, ética e técnica presente nas discussões sobre competência e menciona a dificuldade que existe por parte dos educadores.

Com respeito à relação existente entre moral e política freqüentemente se percebe que os próprios educadores não têm clareza da dimensão política de seu trabalho. Ao interpretarem política como envolvimento partidário, ou mesmo sindical, alguns procuram até negar que tenham algo a ver com isso, invocando uma posição de "apoliticidade" em sua prática (RIOS, 2003, p. 50).

Neste sentido, Saviani, citado por Rios (2003), complementa: "Não se faz política sem competência e não existe técnica sem compromisso; além disso, a política é também uma questão técnica e o compromisso sem com- 
petência é descompromisso" (SAVIANI apud RIOS, 2003, p. 50). O termo competências contempla múltiplos sentidos. Podem ser consideradas como conhecimentos e habilidades adquiridas ao longo do tempo, atitudes na realização de várias tarefas, resultado de experiências adquiridas ao longo da vida, ou ainda, como afirma Perrenoud, citado por Rios (2002): [...] "as competências utilizam, integram, mobilizam conhecimentos para enfrentar um conjunto de situações complexas. A competência implica, também, uma capacidade de atualização de saberes" (PERRENOUD, 2002 apud RIOS, 2002, p.77).

Com base nessa crença, pode-se afirmar que o agir competente significa: "capacidade de mobilizar, articular e colocar em ação valores, conhecimentos e habilidades necessários para o desempenho eficiente e eficaz de atividades requeridas pela natureza do trabalho" (CONSELHO NACIONAL DE EDUCAÇÃO, 1999). Ou ainda, conforme, Cordão (2010, p. 38):

É a capacidade de articular e mobilizar conhecimentos e habilidades que deve ser levada em consideração. Eu tenho que ver que conhecimentos são necessários para desenvolver aquela competência, porque competência implica capacidade de articular conhecimentos, habilidades, atitudes, valores, emoções.

Perrenoud (2000, p. 2) comenta, em entrevista para a Universidade de Genebra, que ao se falar em competência, nas escolas, dá-se prioridade aos recursos: a preocupação maior é com a essência e as situações mais complexas ficam em segundo plano. Trabalhar por competências requer desafiar os alunos a mobilizar seus conhecimentos, propor problemas e projetos.

Nesse sentido, Rios (2002, p. 78) define competências como: "capacidades que se apóiam em conhecimentos". Já em seu livro Ética e competência, Rios explica que competência está associada ao saber fazer bem, o que, em princípio, aproxima-se da posição dos educadores que apresentam esse saber fazer bem em uma dupla dimensão: técnica e política (RIOS, 2003, p. 46). Nesse aspecto, Macedo (2008) define as competências em três sentidos: "pedir", "pedir com" e " pedir contra". O autor considera o termo competência um ato de pedir ou desejar. É uma vontade de realização estabelecida por alguém que tenha autoridade para tal.

Por sua vez, Cordão (2010), em entrevista à revista Educação Profissional: Ciência e Tecnologia leva à reflexão de que o objetivo da educação profissional é desenvolver competências para a destreza profissional competente. Assim, pode-se considerar como válida a avaliação por competências desenvolvida no mundo do trabalho, no desenvolvimento da função, e não na escola. É no mercado de trabalho que se colocará em prática o aprendido, portanto é nesse momento que se pode considerar a avaliação das competências: 
A escola avalia evidências de desempenho e competência, mas não avalia o desempenho e a competência. Porque, mesmo que o aluno desenvolva uma determinada tarefa ou uma prática profissional, ele vai desenvolver numa situação de laboratório (CORDÃO, 2010, p. 39).

Para que o aluno demonstre ter conhecimento do que está realizando, é possível que repita várias vezes o que está fazendo, que seja exatamente igual todas as vezes ou de maneiras diferentes. Para a escola, ele estará explicitando que conseguiu desenvolver tais competências, mas a prova concreta desses conhecimentos, habilidades e atitudes, somente será possível de ser implantada fora do contexto escolar, ao ingressar no mercado de trabalho. $\mathrm{O}$ ideal seria trabalhar de maneira integrada, porque o conhecimento informa a prática e a prática informa o conhecimento tecnológico (CORDÃO, 2010, p. 38). Sendo assim, Rios sinaliza que:

Competências são capacidades que se apóiam em conhecimentos. A capacidade de envolver os alunos em suas aprendizagens, por exemplo, vai requerer o conhecimento do desenvolvimento cognitivo dos alunos, o conhecimento do conteúdo que se vai levar ao aluno (RIOS, 2002, p. 78).

Entretanto, Manfredi (2002) esclarece que as visões e representações entre trabalho, profissão e escola são muito distintas.Trabalho está associado à ideia de emprego ou remuneração. Portanto,

De um lado, estão as representações que denotam negatividade, mediante a subestimação da importância da escola e a supervalorização da experiência, dos saberes e do savoirfaire adquiridos no mundo do trabalho; de fato, muitas pessoas ainda acreditam que a imersão em atividades de trabalho constitua "a verdadeira escola (MANFREDI, 2002, p. 31).

As visões idealizadas da escola em relação ao mundo do trabalho estão associadas à ideia de que a escola é o meio principal para se ter a formação profissional e ingressar no mercado de trabalho, embora exista uma grande diferença no que se ensina na escola e as reais dificuldades enfrentadas no mundo do trabalho.

Rios (2002) indica que as competências são elaboradas de acordo com as demandas do mercado. Diante das competências, vale ressaltar o papel desafiador do professor da educação profissional, que está diante das competências, das mudanças no setor produtivo e das mudanças na educação. Mas quem leciona na educação profissional é o professor ou o instrutor?

\subsection{Professor ou instrutor da educação profissional?}

Os professores da educação profissional geralmente são contratados como instrutores, mas de onde surgiu essa denominação? Utilizando-se 
de Kuenzer (2008) para pensar a função de instrutor, pode-se dizer que nos modelos taylorista e fordista o trabalhador que iniciava suas atividades em determinada empresa utilizava-se da observação de trabalhadores mais experientes para criar o seu conhecimento, ou seja, utilizava-se da memorização para desenvolver seu trabalho.

Kuenzer (2008, p. 28) afirma que nas empresas o instrutor é aquele trabaIhador mais antigo, que possui o conhecimento tácito advindo dos longos anos de experiência. Esse trabalhador é que vai ensinar esses conhecimentos para seu novo colega de trabalho. Então, é chamado de instrutor, e não de professor, pelo fato de não utilizar conhecimentos intelectuais.

No taylorismo-fordismo, o instrutor era aquele que dominava o saber vindo da experiência, o qual não era necessariamente sustentado em formação científico-tecnológica consistente. Para sua formação pedagógica, considerava-se suficiente uma complementação de curta duração, porque o que ele tinha para ensinar vinha da sua experiência (KUENZER, 2008, p. 27).

Ainda é possível ouvir professores da educação profissional que não sentem a necessidade de ter essa formação pedagógica, porque acreditam ser suficiente o seu saber prático, ou seja, o conhecimento tácito. Na pesquisa Ensino Médio Articulado com a Educação Profissional: Currículo, Empregabilidade e Prática Docente (MURARA, 2013), os egressos entrevistados comentam que, embora seja admirável o conhecimento que os professores têm em relação ao mercado de trabalho, muitos têm dificuldade ao expor esses conhecimentos, o que dificulta o entendimento dos alunos.

Os professores da educação profissional, ainda de acordo com a pesquisa de Murara (2013), têm uma relação mais próxima com seus alunos, exatamente pelo fato de que os professores têm muito conhecimento em relação ao mercado de trabalho e os alunos se sentem muito à vontade com o professor, pois é como se fossem colegas. Muitas vezes, sem perceber, os professores utilizam essa aproximação por meio das relações de trabalho como uma estratégia didática.

Kuenzer (2008, p. 28) salienta que a educação profissional necessita de um novo tipo de professor, porque o conhecimento tácito advindo do modelo taylorista e fordista já se tornou insuficiente para os dias atuais. Diante disso, novas demandas aparecem para a educação profissional e, consequentemente, para os professores que nela atuam.

Em síntese, o conhecimento tácito é orgânico a um modo de organizar e gerir o trabalho que se estrutura sobre a relativa estabilidade dos processos, em face da reduzida dinamicidade da tecnologia sobre a fragmentação dos processos e sobre o saber fazer (KUENZER, 2008, p. 28). 
No entanto, o atual contexto profissional lida com processos produtivos e de serviços ultradinâmicos. Esse novo cenário requer formação capaz de ir além dos conhecimentos acumulados pela rotina ao longo da vida. Faz-se imperativo buscar competências que estejam ligadas à resolução de diversos tipos de situações. Capacidade de trabalhar não só pela reprodução ou memorização, mas trabalhar com o intelecto, no sentido de criar, inventar, flexibilizar, realizar mesmo diante do inusitado.

Kuenzer sinaliza que "A especificidade que as mudanças no mundo trabalho conferem à educação profissional é a lógica da polarização de competências, ou seja, preparar para atender às demandas dos diferentes pontos da cadeia produtiva [...]" (KUENZER, 2008, p. 31). Nesse sentido, cabe um novo perfil de professor. No entanto, a autora também alerta sobre a falta de homogeneidade nas políticas de formação de professores da educação profissional, que ainda não possui um consagrado sistema ou diretrizes que norteiem essa formação.

[...] Assim é que as exigências para o exercício da docência nas Universidades e Cefets, por exemplo, incluem qualificação específica em mestrado e em doutorado, tendo em vista o desenvolvimento da pesquisa, ou pelo menos em cursos de licenciatura, tendo em vista a capacitação para a docência, além da dedicação integral e exclusiva (KUENZER, 2008, p. 31).

A autora complementa, ainda, que no caso dos Centros Federais de Educação Tecnológica (Cefets), agora denominados Institutos Federais, existem planos de carreira e condições para que os professores possam se qualificar; porém, isso não se dá de forma eficaz com os instrutores que são contratados por Organizações Não Governamentais (ONGs) ou outras instituições de educação profissional. Geralmente Kuenzer (2008) explica que nesses cursos não se tem uma relação de trabalho estável e adequada. "De modo geral, o trabalho docente é precarizado, quando se trata de educar para o trabalho precarizado" (KUENZER, 2008, p. 32). Para os cursos de curta duração, a contratação costuma ser de instrutores que na grande parte das vezes não possui formação específica e geralmente não têm licenciaturas e não se aperfeiçoam como professores.

Diante dessa situação, Kuenzer (2008, p. 32) alerta que, embora seja difícil qualificar esses professores, devido ao grande ramo de áreas, existe, sim, a necessidade de fazer políticas e estratégias que atendam a esse público.

No Quadro1, a seguir, podem ser observadas as três dimensões que a autora considera como essenciais para a formação de professores da educação profissional: 


\section{Quadro 1 - Dimensões para a formação de professores da educação profissional}

Conhecer o mundo do trabalho sem ingenuidades, a partir da apreensão do caráter de totalidade das relações sociais e produtivas

Clareza a respeito de qual educação profissional se está falando, uma vez que ela atende diversos níveis, da básica a científico-tecnológica de alto nível incluindo os níveis de mestrado e doutorado

Existência de conhecimentos elaborados através de pesquisas realizadas nas últimas décadas que permitam configurar uma pedagogia do trabalho adequada ao caso brasileiro, a ser considerada na elaboração de programas de formação de professores da educação profissional

Fonte: Kuenzer (2008, p. 31-32).

Diante das três dimensões apresentadas, passa-se à discussão acerca da Resolução n. 02/97 e tramitação do Parecer 05/2006. A Resolução 02/97 aborda questões referentes a programas especiais de formação pedagógica de docentes para as disciplinas do currículo do ensino fundamental, do ensino médio e da educação profissional em nível médio. Segundo a Resolução:

Art. 10 - A formação de docentes no nível superior para as disciplinas que integram as quatro séries finais do ensino fundamental, o ensino médio e a educação profissional em nível médio, será feita em cursos regulares de licenciatura, em cursos regulares para portadores de diplomas de educação superior e, bem assim, em programas especiais de formação pedagógica estabelecidos por esta Resolução.

Parágrafo único - Estes programas destinam-se a suprir a falta nas escolas de professores habilitados, em determinadas disciplinas e localidades, em caráter especial (BRASIL, 1997, p. 1).

A intenção de qualificar os professores da educação profissional é essencial, porém, existem muitos fatores envolvidos. A educação profissional possui muitas áreas, o que dificulta ter apenas um curso de licenciatura para atender essa demanda, nesse sentido Carvalho e Souza (2014, p. 888) complementam ao dizer que:

Esta complexidade na oferta de educação profissional e tecnológica, abrangendo níveis e modalidades distintos, não veio acompanhada de políticas de formação docente. Ao contrário, as discussões atuais acerca da docência para EPT identificam um histórico de fragmentação, improviso e insuficiência de formação pedagógica na prática de muitos desses professores.

E depois, tem toda a questão prática proporcionada pela própria experiência de trabalho. Kuenzer (2008, p. 34) explica essa dificuldade quando argumenta que: 
De pouco adianta qualificar tecnicamente o professor se ele não tiver uma ampla compreensão acerca da natureza do trabalho, tal como ele se dá no regime de acumulação flexível, para o que contribui decisivamente o conhecimento das categorias da pedagogia do trabalho.

Nesse sentido, a autora expõe que a Resolução n. 02/97 precisa ser revista, embora encaminhamentos estejam sendo feitos, por exemplo, o Parecer $n$. 5/2006, para o qual não foi encontrada a homologação e traz à tona a necessidade de ser formado em cursos de licenciatura para que se possa dar aulas tanto para educação básica quanto para profissional.

No entanto, Kuenzer (2008, p. 35) traz reflexões e alternativas referentes a esse Parecer. O artigo oitavo do Parecer n. 5/2006 aborda que os cursos de licenciatura terão, no mínimo, 2.800 horas de trabalho acadêmico, sendo que 300 horas devem ser destinadas ao estágio supervisionado e 2.500 horas para as outras atividades formativas.

Já o 9o artigo orienta que:

A formação de docentes no nível superior para a docência
nos anos finais do Ensino Fundamental, no Ensino Médio e na
Educação Profissional de nível médio, destinada a portadores
de diploma de Educação Superior, far-se-á numa das seguin-
tes formas: a) Aproveitamento de estudos e conseqüente-
mente pela integração nos projetos regulares das licenciaturas
mantidas pelas instituições de ensino; b) Programas Especiais
de Formação Pedagógica de Docentes (CONSELHO NACIO-
NA DE EDUCAÇÃO, 2006).

Sendo assim, o artigo $12^{\circ}$ alerta que para qualquer das duas formas descritas no artigo 9o é necessário que as licenciaturas obedeçam à carga horária mínima de 800 horas, sendo, no mínimo, 300 horas destinadas a estágio supervisionado e 500 horas para as demais atividades. Os programas especiais de formação docente terão certificação por meio de apostilamento no diploma de graduação. "O apostilamento de que trata o caput deste artigo é considerado como grau de licenciatura plena para todos os fins" (CONSELHO NACIONAL DE EDUCAÇÃO, 2006, p. 6).

Diante do exposto no Parecer, Kuenzer (2008, p. 35) questiona: "Quem seria o aluno a se matricular nessa licenciatura? A multiplicidade de áreas, modalidades e níveis de Educação profissional tornam inviável a proposição de uma licenciatura em educação profissional de caráter genérico". Sendo assim, seria inviável fazer uma licenciatura para cada área ou especificidade da educação profissional, pois seriam muitas licenciaturas, e talvez não teria demanda para essa diversidade. Nesse sentido, encontra-se a alternativa proposta no Parecer n. 02/97, em seu artigo 1ํo, o qual dá indicação aos programas especiais. 
A partir desta constatação, o Parecer aponta como alternativa a oferta de habilitações especializadas por componente curricular para o caso do ensino médio integrado, ou por campo de conhecimento ou campo de atuação profissional, no caso da educação professional (KUENZER, 2008, p. 35).

Kuenzer (2008) esclarece, ainda, que seria interessante haver certa conexão entre a licenciatura e a formação técnica de nível médio e experiência profissional na área em que irá lecionar, para que esse professor tenha a capacidade de compreender o amplo processo do mercado de trabalho. Nesse sentido, fica a reflexão:

Em que pese a concepção proposta pelo parecer, permanece a questão que permeou a discussão da Res. 02/97: é possível assegurar formação de qualidade para a docência com 500 horas dedicadas a apropriação do conhecimento científico - tecnológico relativo à docência? Não se estará, embora de forma menos aligeirada, apenas oferecendo complementação pedagógica em vez de licenciatura? Ao considerar os eixos propostos pela Res. 02/97 - contextual, de fundamentação e metodológico - não parece tempo suficiente (KUENZER, 2008, p. 37).

Como se pode observar, a formação de professores da educação profissional ainda não tem os rumos bem-definidos. Essa falta de rumo, de certa forma, prejudica tanto o professor como os alunos, que necessitam de professores que tenham domínio dos conhecimentos didático-pedagógicos para a docência. Kuenzer (2008, p. 38) sugere que se pense em cursos de especialização em Pedagogia do Trabalho, com vistas a dominar a Ciência da Educação, mas com foco no trabalho.

Outra alternativa mencionada "[...] é a formulação de um programa de formação em nível nacional, planejado e executado de forma compartilhada pelas IES e Cefets organizado e financiado a partir da SETEC enquanto política pública" (KUENZER, 2008, p. 39). Na questão da formação de professores da educação profissional, pouco se evoluiu no que se refere a políticas públicas que solucionem a questão da habilitação e formação pedagógica para esses professores.

Essa discussão em torno dos professores da educação profissional tem seu início marcado na LDB de 1961, a primeira a mencionar normas para registros de professores do ensino profissional. Machado (2008, p. 70) afirma que foi oficializado pela LDB de 1961 que a formação dos professores do ensino técnico seria em curso especial, diferente dos demais professores. "De forma que até hoje a referência mais forte que se tem é a de que a formação docente para a educação profissional deve se dar em cursos especiais" (MACHADO, 2008, p. 70). Diante do exposto na LDB de 1961 em seu artigo 59, sobre os cursos especiais, em 1967, foi publicado o Parecer CFE n. 12/1967, o qual propunha que os cursos especiais fossem para formar professores de 
disciplinas específicas e, em 1968, a Portaria Ministerial complementava o que estava escrito no Parecer, dizendo que os cursos especiais eram para quem já possuía diploma de nível superior ou técnico.

Machado (2008, p. 71) esclarece que a educação profissional era diferenciada por áreas, como comercial, agrícola e industrial, e que muitos pareceres e portarias foram criados a fim de regularizar a situação dos professores da educação profissional. Essas legislações podem ser observadas no Quadro 2:

\section{Quadro 2 - Legislações que regulamentam a formação de professores da educação profissional}

\begin{tabular}{|c|c|}
\hline $\begin{array}{l}\text { Lei } n . \\
2.024 / 1961 \\
\text { (LDB) }\end{array}$ & $\begin{array}{l}\text { Trata da questão unicamente para assinalar que } \\
\text { seria preciso separar formalmente os lugares da } \\
\text { formação de professores para o ensino médio e } \\
\text { da formação de professores de disciplinas especí- } \\
\text { ficas do ensino médio técnico. }\end{array}$ \\
\hline $\begin{array}{l}\text { Parecer CFE n. } \\
257 / 1963\end{array}$ & $\begin{array}{l}\text { Aprova o Curso Especial de Educação Técnica em } \\
\text { Cultura Feminina (magistério destinado para área } \\
\text { de Economia Doméstica e Trabalhos Manuais). }\end{array}$ \\
\hline $\begin{array}{l}\text { Portaria MEC } n . \\
174 / 1965\end{array}$ & $\begin{array}{l}\text { Curso de Didática do Ensino Agrícola (formação } \\
\text { pedagógica de professores das disciplinas de } \\
\text { cultura técnica). }\end{array}$ \\
\hline $\begin{array}{l}\text { Parecer CFE n. } \\
479 / 1968\end{array}$ & $\begin{array}{l}\text { Explica que os cursos especiais de educação téc- } \\
\text { nica previstos no art. } 59 \text { da LDB eram para formar } \\
\text { professores de disciplinas específicas. }\end{array}$ \\
\hline $\begin{array}{l}\text { Lei } n . \\
5.540 / 1968 \\
\text { (Reforma } \\
\text { Universitária) }\end{array}$ & $\begin{array}{l}\text { Representou uma flexão da tendência que vinha } \\
\text { se formando, pois estabelecia uma duração fixa } \\
\text { para a formação de professores do ensino médio } \\
\text { e que a formação de professores de disciplinas } \\
\text { específicas do ensino médio técnico precisava } \\
\text { obedecer a um currículo mínimo. (MACHADO, } \\
2008, \text { p. 71) }\end{array}$ \\
\hline $\begin{array}{l}\text { Decreto-lei } n . \\
655 / 1969\end{array}$ & $\begin{array}{l}\text { Determinou que a formação de professores para } \\
\text { o ensino de segundo grau, de disciplinas gerais } \\
\text { ou técnicas teria que se dar somente em curso } \\
\text { superior. (MACHADO, 2008, p.71) }\end{array}$ \\
\hline $\begin{array}{l}\text { Decreto-Lei } n . \\
655 / 1969\end{array}$ & $\begin{array}{l}\text { Organização de cursos de formação de professo- } \\
\text { res para o ensino técnico. }\end{array}$ \\
\hline
\end{tabular}

Fonte: Machado (2008). 
Este quadro mostra as primeiras iniciativas em relação ao tema. Muitos outros decretos, portarias e pareceres foram sendo criados para regularizar a situação dos professores da educação profissional nos anos 1970 e 1980.

Vale ressaltar aqui a LDB de 1996, que diferente da LDB de 1961, nem menciona a questão da formação para os professores da educação profissional. Como comenta Machado (2008, p. 79), a Lei se refere à formação de forma ampla e não se atém a essa questão.

O Decreto n. 2.208/1997 também não se impõe a essa questão, tanto que Machado (2008, p. 79) afirma que: "Ele representa até um retrocesso com relação aos dispositivos anteriores sobre formação docente para a educação profissional". Essa afirmação da autora está pautada no artigo 9o do Decreto, o qual parece indicar que qualquer pessoa possa ser professora desde que tenha experiência no mercado de trabalho.

É o caso de conhecer a atual situação dos professores desta modalidade educativa e definir uma política nacional

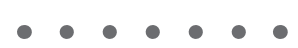

No seu art. 9o chega ao despropósito de dizer que as disciplinas do currículo do ensino técnico são ministradas por professores, instrutores e monitores selecionados, principalmente, em função de sua experiência profissional. Talvez, se prevenindo das possíveis críticas, o decreto diz que estes deverão ser preparados para o magistério, previamente ou em serviço, por meio de cursos regulares de licenciatura ou programas especiais de formação pedagógica. Percebe-se, claramente, a intenção de valorizar a dimensão da experiência prática em detrimento de uma formação teórica e pedagógica mais consistente (MACHADO, 2008, p. 79).

Nesse mesmo ano, 1997, com o que se tinha determinado em relação aos programas especiais no Decreto n. 2.208/97, surge a Resolução n. 02/97, que dispõe sobre esses programas especiais para os docentes da educação profissional que já possuíam curso superior, sendo que a carga horária seria de 540 horas com teoria e prática. "Chamo a atenção para esse detalhe: houve um rebaixamento significativo da carga horária comparativamente ao que se vinha sendo praticado nos cursos especiais de formação docente [...]" (MACHADO, 2008, p. 80). A Resolução n. 02/97, segundo Machado (2008), previa uma avaliação no período de até até cinco anos, o que não se concretizou.

Machado (2008, p. 81) considera, ainda, que a Resolução n. 02/97 não atende com eficácia às necessidades para a formação de professores da Educação Profissional. A autora considera que não vem ao caso fazer essa avaliação, que deveria ter sido feita até cinco anos após a publicação, é o caso de conhecer a atual situação dos professores desta modalidade educativa e definir uma política nacional que os reconheça e os valorize.

De acordo com os dados do INEP (2015), os Institutos Federais têm 17.814 professores, dos quais 934 possuem somente graduação; 2.804, cursos de 
especialização; 8.661 possuem mestrado e 5.413, doutorado. Porém, os dados do INEP não mencionam se esses professores possuem formação didático-pedagógica e se eles atuam em sua área de formação. Os dados do INEP não mencionam o número de docentes atuantes nas instituições privadas.

O número de professores que trabalham com a Educação Profissional e Técnológica é expressivo, esses dados potencializam a urgência de políticas públicas que deem suporte aos docentes.

\section{Considerações finais}

Com o crescimento da educação profissional e tecnológica no Brasil, criação de Institutos Federais, incentivo a instituições privadas que oferecem cursos direcionados à educação profissional, a impressão que se tem é que pouco se tem investido na formação de professores. A parte didática e pedagógica desses professores está ficando um pouco à mercê das novas demandas do mercado. Como política pública da modalidade, a formação de professores para a educação profissional ainda não tem os rumos bem-definidos. Essa falta de rumo, de certa forma, prejudica tanto o professor como os alunos, que necessitam de professores competentes tanto em relação ao domínio dos conhecimentos didáticos pedagógicos quanto ao domínio dos conhecimentos técnicos e políticas da área.

Investimento em infraestrutura e laboratórios é essencial para o desenvolvimento de tecnologia e inovação, porém, a dúvida que fica é: Como está a qualidade da formação dos professores da Educação Profissional e Tecnológica? Não seria um momento oportuno de rever e trazer à tona a questão da formação desses professores?

Apesar de ser um grande desafio qualificar esses profissionais, devido à diversidade de áreas, é necessário, sim, pensar em políticas de formação de professores para a Educação Profissional e Tecnológica. Tendo em vista o grande interesse atual em investir nesta modalidade, dadas as necessidades do País em relação tanto ao mercado interno quanto ao mercado internacional, urge que políticas de maior investimento e com maior consistência sejam definidas para esta modalidade educativa, particularmente em relação à formação de professores. Considera-se este um grande passo e um grande desafio para o desenvolvimento do Brasil como um todo.

\section{Referências}

BRASIL. Lei n. 4.024, de 20 de dezembro de 1961. Fixa as Diretrizes e Bases da Educação Nacional. Diário Oficial da União, Brasília, DF, 27 dez. 1961. Disponível

B. Téc. Senac, Rio de Janeiro, v. 43, n. 2, p. 84-101, maio/ago. 2017. 
em: <http://wwwp.fc.unesp.br/ lizanata/LDB\%204024-61.pdf>. Acesso em: 19 jul. 2013.

BRASIL. Lei n. 9.394, de 20 de dezembro de 1996. Estabelece as diretrizes e base da educação nacional. Diário Oficial da União, Brasília, DF, 23 dez. 1996. Disponível em: <http://www.planalto.gov.br/ccivil_03/leis/L9394.htm\#art92>. Acesso em: 10 maio 2012.

BRASIL. Ministério da Educação. Secretaria de Educação Fundamental. Parâmetros curriculares nacionais: introdução aos parâmetros curriculares nacionais. Brasília, DF, 1997.

CARVALHO, O. F.; SOUZA, F. H. M. Formação do docente da educação profissional e tecnológica no Brasil: um diálogo com as faculdades de educação e o curso de Pedagogia. Educação e Sociedade, Campinas, v. 35, n. 128, p. 629-996, jul./set. 2014.

CONSELHO NACIONAL DE EDUCAÇÃO (Brasil). Câmara de Educação Básica.

Resolução CNE/CEB n 04, de 5 de outubro de 1999. Institui as Diretrizes Curriculares Nacionais para a Educação Profissional do Nível Técnico. Brasília, DF, 1999.

CONSELHO NACIONAL DE EDUCAÇÃO (Brasil). Conselho Pleno. Parecer CNE/CP

n. 5/2006, de 4 de abril de 2006. Aprecia Indicação CNE/CP n. 2/2002 sobre Diretrizes Curriculares Nacionais para Cursos de Formação de Professores para a Educação Básica. Brasília, DF, 4 abr. 2006.

CORDÃO, F. 0 panorama da educação profissional no Brasil. Educação Profissional: ciência e tecnologia, Brasília, DF, v. 4, n. 1, p. 37-41, 2010.

DELUIZ, Neise. 0 modelo das competências profissionais no mundo do trabalho e na educação: implicação para o currículo. Boletim Técnico do Senac, Rio de Janeiro, v. 27, n. 3, 2001. Disponível em: < http://www.senac.br/BTS/273/boltec273b.htm>. Acesso em: 10 maio 2012.

FORMAÇÃO de professores para a educação profissional e tecnológica: Brasília, 26, 27 e 28 de setembro de 2006. Brasília, DF: Inep, 2008. (Educação superior em debate, v. 8).

INEP. Sinopse estatística da educação superior. Brasília, DF, 2015. Disponível em: <http://portal.inep.gov.br/web/guest/sinopses-estatisticas-da-educacao-superior>. Acesso em: 22 jun. 2016.

KUENZER, A. Z. Educação profissional: categorias para uma nova pedagogia do trabalho. Boletim Técnico do Senac, Rio de Janeiro, v. 25, n. 2, p. 19-29, maio/ago. 1999.

KUENZER, A. Z. Palestra. In: FORMAÇÃO de professores para a educação profissional e tecnológica: Brasília, 26, 27 e 28 de setembro de 2006. Brasília, DF: Inep, 2008. p. 19-40.

MACEDO, Lino de. Competências na educação. São Paulo: Secretaria de Educação do Estado de São Paulo, 2008. Disponível em: <http://www.rededosaber.sp.gov.br/ 
contents/SIGS-CURSO/sigsc/upload/br/site_25/File/competencias_na_educacao_ cr.pdf>. Acesso em: 20 abr. 2012.

MACHADO, Lucília Regina de Souza. Palestra. In: FORMAÇÃO de professores para a educação profissional e tecnológica: Brasília, 26, 27 e 28 de setembro de 2006. Brasília, DF: Inep, 2008. p. 67-82.

MANFREDI, Silvia Maria. Educação profissional no Brasil. São Paulo: Cortez, 2002.

MURARA, Patricia. Ensino médio articulado com a educação profissional: currículo, prática docente e empregabilidade. Dissertação (Mestrado em Educação) Universidade do Vale do Itajaí, Itajaí, 2013.

PERRENOUD, Philippe. Construindo competências: depoimento. Entrevista concedida a Paola Gentile e Roberta Bencini. Nova Escola, São Paulo, p. 19-31, set. 2000.

REGATTIERI, M.; CASTRO, J. M. (Org.). Ensino médio e educação profissional: desafios da integração. Brasília, DF: Unesco, 2010.

RIOS, Terezinha A. Compreender e ensinar: por uma docência da melhor qualidade. 3 ed. São Paulo: Cortez, 2002.

RIOS, Terezinha A. Ética e competência. 13. ed. São Paulo: Cortez, 2003. 


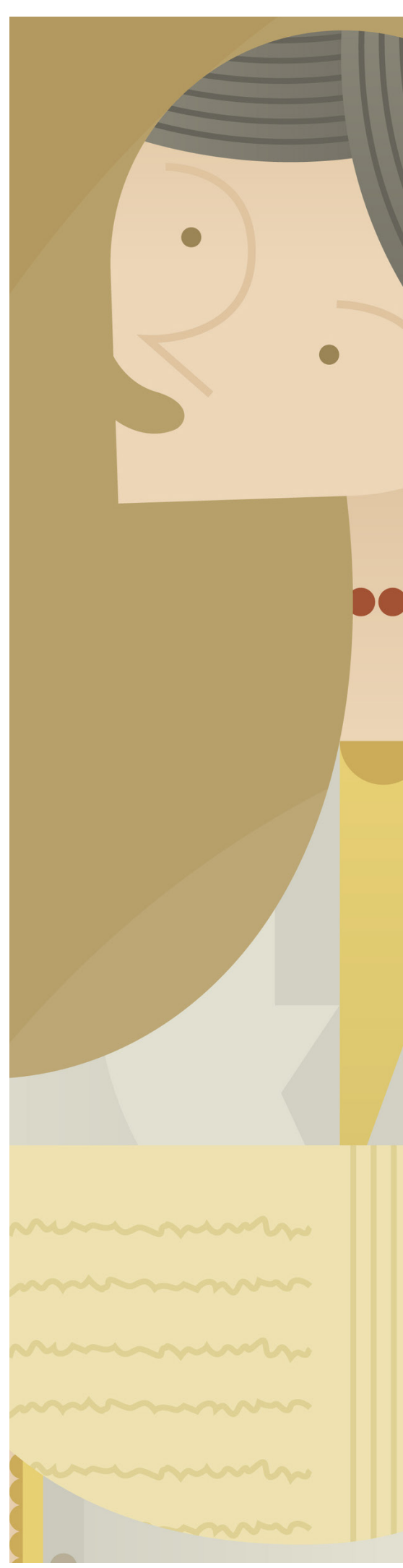

B. Téc. Senac, Rio de Janeiro, v. 43, n. 2, p. 84-101, maio/ago. 2017. 